\title{
One-trial simultaneous and backward fear conditioning as reflected in conditioned suppression of licking in rats
}

\author{
WILLIAM J. MAHONEY and JOHN J. B. AYRES \\ University of Massachusetts, Amherst, Massachusetts 01002
}

\begin{abstract}
In three experiments, groups of albino rats received one strictly simultaneous pairing of a 4-sec auditory conditioned stimulus (CS) and a 4-sec 1-mA shock unconditioned stimulus (US). Other groups received a backward pairing, in which the US began before the CS, or a forward pairing, in which the CS began before the US. Control groups received only the US or received both the CS and the US but widely separated in time. Later, the CS was presented while the rats licked a drinking tube for water, and CS-elicited suppression of licking was taken as an index of the Pavlovian conditioned response (CR). It was found that groups receiving a single forward or a single simultaneous pairing suppressed more than groups that had received a backward pairing; and the backward groups, in turn, suppressed more than the control groups. It appears, then, that excitatory fear conditioning, as reflected in conditioned suppression of licking in rats, can be produced in a single trial by both backward and simultaneous conditioning procedures.
\end{abstract}

Evidence has been presented that simultaneous and backward pairings of conditioned stimuli (CSs) and unconditioned stimuli (USs) can result in excitatory conditioned responses (CRs) (Heth \& Rescorla, 1973; Matsumiya, 1960; Mowrer \& Aiken, 1954). Despite this evidence, a long standing skepticism (Harris, 1941; Pavlov, 1927) of the associative nature of these CRs continues (Cautela, 1965; Plotkin \& Oakley, 1975; Tarpy, 1975). Criticisms of studies purporting to have demonstrated excitatory CRs following simultaneous or backward pairings usually focus on the inadequacies of the control procedures (Cautela, 1965; Harris, 1941; Plotkin \& Oakley, 1975). It has been suggested that increased responding following simultaneous or backward pairings may be due to some nonassociative process. The present experiments attempt to demonstrate excitatory conditioning as a result of simulcaneous or backward pairings in a way not readily subject to these criticisms.

A feature of these experiments is that they assess the effect of a single simultaneous or backward trial. Whether excitatory simultaneous or backward conditioning can be demonstrated in only one trial seems intrinsically interesting, but the one-trial procedure seems to offer two further advantages over the usual

This research was presented at the meeting of the Eastern Psychological Association, Philadelphia, Pennsylvania, 1974. It was supported by Grant GB-36982 from the National Science Foundation to John J. B. Ayres. We wish to thank J. Averill, J. W. Donahoe, and J. W. Moore for their comments on earlier drafts of the manuscript. Requests for reprints should be addressed to William J. Mahoney, Psychology Department, Middlesex House, University of Massachusetts, Amherst, Massachusetts 01002 . multitrial procedure. First, it eliminates entirely the possibility that conditioning involves remote associations between a CS on trial $n$ and a US on trial $n+1$ (or the converse). Second, it reduces the experimental treatment to its barest essentials, simplifying the control procedures designed to leave the CS neutral and reducing the list of potential controls.

\section{EXPERIMENT I}

The first experiment assessed the effect of a single simultaneous pairing of a noise CS and an electric shock US on the performance of thirsty rats licking a water bottle. Previous research using this technique (e.g., Vogel \& Spear, 1966) has shown that CSs from forward conditioning produce suppression of licking, and suppression of licking has been taken as evidence for excitatory conditioning.

\footnotetext{
Method

Subjects. Sixteen 80 - to 90 -day-old albino rats were housed individually and fed and watered freely for 10 days before the start of water deprivation.

Apparatus. One Gerbrands' Model B conditioning chamber housed in a ventilated $0.61-\mathrm{m}$ cube of $12.7-\mathrm{mm}$ plywood lined with acoustical tile was used. The chamber was lit by a $28-\mathrm{V}$ cue light located on one wall $10 \mathrm{~cm}$ above the floor and $3 \mathrm{~cm}$ from an adjacent wall. One wall of the conditioning chamber was transparent Plexiglas with a $5.1 \times 1.3 \mathrm{~cm}$ aperture through which a drinking tube was placed. The tube was attached to a bottle containing tap water and to a Grason-Stadler drinkometer, E4690A-1, which registered the licks. The CS was an 81-dB white noise, re $20 \mu \mathrm{N} / \mathrm{m}^{2}$, provided by a Grason-Stadler 455 noise generator and presented through a $10-\mathrm{cm}$ speaker mounted on the chamber lid. The US was a $1-\mathrm{mA}$ scrambled grid shock provided by a Grason-Stadler E1064GS shock source. Events in the experimental chamber were controlled and recorded by a Lehigh Valley computer system in another room.
} 
Procedure. The rats were randomly assigned to two treatment groups to be described below. The day before the first experimental session, their home cage water bottles were removed. Throughout the rest of the experiment, the bottles were replaced for $30 \mathrm{~min}$ each day immediately after the experimental session. The rats were run one at a time with the order of treatments counterbalanced. For the first 4 training days, each rat was placed in the conditioning chamber and allowed to make 110 licks before being removed. On the fifth day, the water bottle was removed for both treatment groups. Rats in the simultaneous conditioning group. Group S, were placed in the chamber, and then, after $30 \mathrm{sec}$, were presented simultaneously with the CS and US for $4 \mathrm{sec}$. Approximately $15 \mathrm{sec}$ later, the rats were returned to their home cages. Animals in the control group, Group C, received the same treatment except that the CS was omitted. This group, then, served as a control for the possible nonassociative effects of an unpaired US. The next 2 days were test days. Each rat was allowed to make 100 licks; then the CS was presented until the animal completed 10 more licks. Dependent measures recorded were the latencies to the first lick, the latency to the 90th lick (recovery time), the time to complete the 90th through the 100th lick (pre-CS time), and the time to complete the 100th through the 110th lick (CS time). These measures were recorded on all but the conditioning day, even though a CS was not presented on the training days.

\section{Results and Discussion}

Table 1 shows the group medians on each of the four dependent measures on the last training day and on the 2 test days. Between-groups differences were evaluated using the Wilcoxon rank sums test. Withingroups differences were evaluated using the Wilcoxon signed ranks test. All tests described in this paper were two-tailed. The groups did not differ in terms of the four dependent measures during the last training session. Also, they did not differ in terms of first lick latency, recovery time, or pre-CS time on the rirst test day. But the CS times of both groups were significantly longer than the pre-CS times on the first test day (Ts $=0$, ps $<.01)$; furthermore, the CS times of Group $\mathrm{S}$ were significantly longer than those of Group $C$ on both test days $(T=39, p<.01$; $T=46, p<.05$; for Test Days 1 and 2, respectively).

Table 1

Median Latencies in Seconds: Experiment I

\begin{tabular}{llll}
\hline & & & \\
& Session & & \\
\cline { 2 - 3 } Group & Last Training & Test 1 & Test 2 \\
\hline
\end{tabular}

\begin{tabular}{|c|c|c|c|}
\hline \multicolumn{4}{|c|}{ First Lick Latency } \\
\hline $\mathbf{S}$ & 25.3 & 309.5 & 206.9 \\
\hline C & 16.4 & 250.2 & 90.4 \\
\hline \multicolumn{4}{|c|}{ Recovery Time } \\
\hline$S$ & 15.9 & 29.4 & $\begin{array}{l}33.7 \\
32 .\end{array}$ \\
\hline C & 15.2 & 22.4 & 33.8 \\
\hline \multicolumn{4}{|c|}{ Pre CS Time } \\
\hline $\mathbf{S}$ & 1.7 & 2.5 & 2.4 \\
\hline C & 1.6 & 2.2 & 2.6 \\
\hline \multicolumn{4}{|c|}{ CS Time } \\
\hline $\mathbf{s}$ & 1.8 & 77.7 & 8.3 \\
\hline C & 1.5 & 6.1 & 3.4 \\
\hline
\end{tabular}

Although both groups suppressed to the CS on the first test day, the difference in degree of suppression suggests that they suppressed for different reasons. The suppression in the control group was probably a reaction to the novelty of the $\mathrm{CS}$. But the greater suppression of the experimental group probably reflects an associative process acting in addition to novelty. An indication of the strength of the suppression of the experimental group is that on the second test day there still was a significant difference $(p<.05)$ between groups even though the experimental group was subjected to a considerably longer extinction procedure because of its prolonged suppression on the first test day.

\section{EXPERIMENT II}

The control group in Experiment 1 controlled for the non-associative effects of presentation of the US in conditioning, but not for possible non-associative effects of the CS. In Experiment 2, a new simultaneous group was compared with control groups in which both CS and US were presented but widely separated in time (explicitly unpaired controls).

\section{Method}

Subjects and apparatus. Twenty-two 75- to 80-day-old Holtzman albino rats were housed individually and fed and watered freely for 10 days before the start of water deprivation. The apparatus was that of Experiment 1 , except that a $1,000-\mathrm{Hz}$ tone, re $20 \mu \mathrm{N} / \mathrm{m}^{2}$, was used as the CS instead of white noise.

Procedure. The procedure was similar to that of Experiment except that only 3 lick-training days, instead of 4 , preceded the conditioning session. On the 4 th day, the water bottle was removed from the conditioning chamber. Each rat was placed in the box for $432 \mathrm{sec}$ and given a 4-sec 1-mA shock US after $214 \mathrm{sec}$ had elapsed. Treatment of groups differed only in the time of presentation of a single 4-sec CS. For the simultaneous group, Group $S(N=8)$, the $C S$ and US were coextensive. For one explicitly unpaired group, Group EUF $(N=7)$, the CS terminated $3 \mathrm{~min}$ prior to US onset. For another explicitly unpaired group, Group EUB $(N=7)$, the CS came on 3 min after US termination. Days 5 and 6 were test days. The test procedure was that of Experiment I.

\section{Results and Discussion}

Table 2 shows the group median scores for all four dependent measures. Statistical analysis of these data (Wilcoxon tests) indicated that the groups did not differ in terms of the four dependent measures during the last training session. Also, they did not differ in terms of first lick latency, recovery time, or pre-CS time on the first test day. But on the first test day, Group S once again suppressed to the CS significantly longer than did the controls $(T=36, p<.02$; $\mathrm{T}=31, \mathrm{p}<.01$; for Groups EUF and EUB). On the second test day, Group $S$ still suppressed longer than Group EUF $\left(T_{0}=34, p<.01\right)$ but not longer than Group EUB. Again, the suppression in the simultaneous group appears to reflect an associative process. The simultaneous group suppressed to the CS more 
Table 2

Median Latencies in Seconds: Experiment II

\begin{tabular}{|c|c|c|c|}
\hline \multirow[b]{2}{*}{ Group } & \multicolumn{3}{|c|}{ Session } \\
\hline & Last Training & Test 1 & Test 2 \\
\hline \multicolumn{4}{|c|}{ First Lick Latency } \\
\hline$S$ & 1.1 & .1 & .2 \\
\hline EUF & 2.3 & .1 & .1 \\
\hline EUB & 3.3 & .1 & 0.0 \\
\hline \multicolumn{4}{|c|}{ Recovery Time } \\
\hline $\mathrm{S}$ & 13.9 & 15.0 & 24.7 \\
\hline EUF & 17.6 & 23.0 & 22.5 \\
\hline EUB & 16.8 & 14.8 & 34.0 \\
\hline \multicolumn{4}{|c|}{ Pre CS Time } \\
\hline$S$ & 1.6 & 1.5 & 1.7 \\
\hline EUF & 1.7 & 1.9 & 2.0 \\
\hline EUB & 1.6 & 2.3 & 2.4 \\
\hline \multicolumn{4}{|c|}{ CS Time } \\
\hline$S$ & 1.7 & 19.4 & 5.9 \\
\hline EUF & 1.7 & 2.5 & 2.4 \\
\hline EUB & 1.8 & 2.3 & 6.8 \\
\hline
\end{tabular}

than the controls did even though all groups were equated in terms of the number of CS and US presentations during experimental treatment. The control groups of Experiment II did not suppress significantly to the CS on the first test day, probably because these controls received exposure to the CS during experimental treatment. Such exposure would obviously reduce the unconditioned suppressive effects of the CS attributable to novelty.

Experiment II also differed from Experiment I in producing shorter first lick latencies during the last training session and especially during the first test session. This difference may reflect the longer exposure to the conditioning chamber following US presentation in Experiment II. If such exposure allowed extinction of fear to the apparatus cues, this reduction of fear would reduce suppression to these cues in the following test session. The shorter latencies during the last training session cannot, however, be similarly explained.

\section{EXPERIMENT III}

Experiments I and II demonstrated one-trial simultaneous fear conditioning using conditioned suppression as the indicant response. In Experiment III, the same one-trial procedure was used to investigate the effect on fear conditioning of the interstimulus interval or ISI (the interval between CS and US onsets). Previous work in which fear is conditioned over many trials (Heth \& Rescorla, 1973) found strongest conditioning with a positive ISI (CS onset precedes US onset). Conditioning was weaker with a zero ISI (CS and US begin together) and still weaker with increasingly negative ISIs (CS onsets follow US onsets). There has been a suggestion
(Jones, 1962) that with a very few pairings zero or negative ISls might produce stronger conditioning than positive ISIs. Experiment III tested this possibility.

\section{Method}

Subjects and apparatus. Forty-eight 80 - to 90 -day-old Holtzman albino rats were housed individually and fed and watered freely for 10 days before the start of water deprivation. The apparatus was that of Experiment II.

Procedure. The rats were randomly assigned to six groups. For the first 4 days, all groups were placed in the conditioning chamber and allowed 110 licks. On the fifth day, the rats were placed in the chamber with the water bottle removed and, after $180 \mathrm{sec}$, received a 4-sec $1-\mathrm{mA}$ shock US. The groups differed only according to the time of presentation of a single 4-sec tone CS. For Group S, the CS was coextensive with the US. For Group F4, the CS came on $4 \mathrm{sec}$ before US onset. For Group F8, the CS came on $8 \mathrm{sec}$ before US onset. For Group B4, the CS came on $4 \mathrm{sec}$ after US onset. For Group B8, the CS came on $8 \mathrm{sec}$ after US onset. The control group received the CS $150 \mathrm{sec}$ prior to US onset. The entire session was $364 \mathrm{sec}$ long. On the 6 th and 7 th day, the subjects were tested as in Experiments I and II.

\section{Results and Discussion}

Table 3 contains the group median scores for all four dependent measures. Statistical analysis of these

Table 3

Median Latencies in Seconds: Experiment III

\begin{tabular}{|c|c|c|c|}
\hline \multirow[b]{2}{*}{ Group } & \multicolumn{3}{|c|}{ Session } \\
\hline & Last Training & Test 1 & Test 2 \\
\hline \multicolumn{4}{|c|}{ First Lick Latency } \\
\hline F8 & 5.4 & 28.7 & 3.6 \\
\hline F4 & 11.1 & 26.6 & 6.9 \\
\hline$S$ & 8.1 & 9.2 & 124.5 \\
\hline B4 & 11.1 & 21.9 & 3.9 \\
\hline B8 & 7.9 & 12.8 & 2.3 \\
\hline $\mathrm{C}$ & 18.1 & 15.1 & 3.8 \\
\hline \multicolumn{4}{|c|}{ Recovery Time } \\
\hline F8 & 30.2 & 30.3 & 48.2 \\
\hline $\mathrm{F} 4$ & 21.9 & 24.0 & 99.2 \\
\hline$S$ & 29.3 & 46.0 & 95.3 \\
\hline B4 & 24.8 & 29.3 & 45.2 \\
\hline B8 & 31.9 & 38.4 & 53.4 \\
\hline $\mathrm{C}$ & 18.8 & 26.7 & 31.4 \\
\hline \multicolumn{4}{|c|}{ Pre CS Time } \\
\hline F8 & 2.0 & 1.9 & 2.0 \\
\hline F4 & 2.5 & 2.3 & 1.8 \\
\hline $\mathbf{S}$ & 2.9 & 1.7 & 2.6 \\
\hline B4 & 3.6 & 2.5 & 2.3 \\
\hline B8 & 3.2 & 1.8 & 3.0 \\
\hline $\mathrm{C}$ & 2.3 & 1.6 & 2.3 \\
\hline \multicolumn{4}{|c|}{ CS Time } \\
\hline F8 & 2.2 & 136.5 & 16.2 \\
\hline F4 & 2.2 & 92.2 & 54.5 \\
\hline$S$ & 2.2 & 62.2 & 12.4 \\
\hline B4 & 2.1 & 6.2 & 4.8 \\
\hline B8 & 2.4 & 16.1 & 13.6 \\
\hline C & 2.8 & 3.1 & 2.4 \\
\hline
\end{tabular}

*Due to an apparatus failure, the data from two rats in each group were lost on the second test day. 
data (Wilcoxon tests) indicated that the groups did not differ in terms of the four dependent measures during the last training session. Also they did not differ in terms of first-lick latency, recovery time, or pre-CS time on either test day. But after treatment, the two forward groups and the simultaneous group suppressed to the CS significantly longer than the two backward groups and the control (Ts $\leqslant 49$; ps $<.05)$. The two backward groups also suppressed longer than the control group (Ts $\leqslant 49$, ps $<.05$ ). Differences among the two forward groups and the simultaneous group were not reliable, nor was the difference between the two backward groups.

The one-trial procedure did prove to be somewhat sensitive to ISI variation. Although it is impossible from the present data to describe the optimal ISI for one trial fear conditioning, it appears to be in the positive direction. This finding agrees with results of previous work involving several pairings (e.g., Heth \& Rescorla, 1973). It does not support the conjecture that, with only a few pairings, simultaneous and backward procedures should produce stronger conditioning than forward procedures (Jones, 1962).

\section{GENERAL DISCUSSION}

Before relating the present findings to theories of conditioning, and in view of continuing arguments over appropriate controls, we will examine the controls used in this research and question the neutrality of the baselines they provided. Experiment I involved a US-alone control procedure. This procedure is typically used as a control for the nonassociative effects of the US presentation. As used here, it was a control for suppression that might occur to any stimulus following a shock presentation. Note that this was a conservative control procedure since the control group had no experience with the CS prior to testing and would normally be expected to suppress to the CS on first appearance due to its novelty (see, e.g., Domjan \& Siegel, 1971). Because of this unconditioned suppression to a novel CS, the use of this control procedure would tend to underestimate the excitation conditioned to the CS in the experimental group. In spite of this conservative baseline, evidence for excitatory simultaneous conditioning was obtained.

In Experiment II, the control procedure was more similar to the experimental procedure because the control animals had both CS and US in training, but in an explicitly unpaired forward or backward manner. This control gave the rats experience with the CS prior to testing. There are potential and mutually exclusive effects of such an explicitly unpaired procedure. First, through a remote association excitation might be conditioned to the explicitly unpaired CS. Second, because the explicitly unpaired control involves a negative CS-US contingency (Rescorla, 1967), it might cause the explicitly unpaired CS to become inhibitory (Rescorla, 1969; Rescorla \& LoLordo, 1965). The first possibility would lead us to underestimate the conditioning in the experimental conditions; the second possibility would lead us to overestimate it. The first possibility should be of little concern here because in the explicitly unpaired control groups there was no evidence of suppression to the CS. Because the experimental groups suppressed significantly more than the controls, we should be more concerned about overestimating the conditioning in the experimentals than in underestimating it. The second possibility should also give us little cause for concern. First, it now appears (Rescorla \& Wagner, 1972) that it is not the negative CS-US contingency or correlation per se that leads to inhibitory conditioning but rather the nonreinforcement of a CS in compound with excitatory stimuli (an event that occurs frequently, but not necessarily, in procedures involving negative contingencies. Thus, although the CS and US were negatively correlated for both Groups EUF and EUB in Experiment II and for the control group in Experiment III, the explicitly unpaired CS was nonreinforced in compound with an excitatory stimulus only for Group EUB (assuming that the apparatus cues were made excitatory by the US-alone trial). It follows that the CS should not have become inhibitory, at least for Group EUF in Experiment II and for the control group of Experiment III. Finally, since all of the control groups were behaviorally indistinguishable, there is no reason to assume that inhibition conditioned to the explicitly unpaired CS was an important consideration in any of them. It seems reasonable to conclude, therefore, that the control procedures used provided adequate baselines and that the conditioned suppression produced by the one-trial simultaneous and backward procedures reflected a genuine associative process.

The finding that simultaneous and backward conditioning procedures produce reliable excitatory conditioning in one trial appears by and large to be unexpected on the basis of previous reviews of the literature (e.g., Gormezano \& Moore, 1969; Kimble, 1961). Similarly, theoretical descriptions of the classical conditioning process (e.g., Hull, 1943; Pavlov, 1927) have for the most part denied the possibility of the excitatory backward and simultaneous conditioning that the present study and others (Heth \& Rescorla, 1973; Matsumiya, 1960; Mowrer \& Aiken, 1954) subsequently found. There were, however, some theorists who predicted that these procedures would result in excitatory conditioning. For example, Jones (1962) attributed the acquisition of classical aversive conditioning to the joint action of two processes; contiguity between the 
CS and UR, and the reinforcing effect of the US on the CR. Both processes were assumed to be bidirectional. That is, their effects were thought to be strongest when the time intervals involved, CS-UR and CR-US, were zero; and their effects were thought to decrease uniformly as the intervals lengthened in any direction. These assumptions imply that early in acquisition, conditioning is due solely to the contiguity of the CS and the UR. The principle of reinforcement does not become important until later because, early in conditioning, there is no $\mathrm{CR}$ to be reinforced. Therefore, the optimal ISI for conditioning early in training would be one in whch the CS-UR interval is zero. Given that the UR must follow the onset of the US by a finite amount of time, Jones concluded that a backward pairing of the CS and US should be optimal. The present results support Jones' expectation of excitatory backward conditioning, but show that, even with only one pairing, the forward procedure is more, not less, effective.

It is possible to account for the present results with a modification of Jones' two-process theory if it is assumed that the initial onset of the CS is, itself, a fearful or startling event which elicits an unconditioned fear response similar to the UR elicited by the shock. This fear response to the CS in the backward groups would not be reinforced since it would not occur until after the US had been presented. Therefore, it is possible that in the onetrial procedure, the gradients of contiguity of the $C S$ and UR and the gradient of reinforcement of the postulated UR to the CS summate to produce strong conditioning in the forward group in which both CS-UR contiguity and reinforcement of the postulated UR occur. But, in the backward groups, in which no reinforcement occurs, the amount of excitatory conditioning is less.

A test of the above hypothesis is suggested by the following considerations: The analysis predicts that with few CS preexposures the postulated unconditioned fear response to the CS would be habituated. To that extent, it would not occur during a subsequent CS-US pairing and therefore could not be reinforced by the US. Thus the strength of excitatory conditioning produced by a forward pairing relative to a backward pairing should be reduced.

Many of the more contemporary views of the ciassical conditioning process emphasize predictive CS-US relationships. As Heth and Rescorla (1973) have noted, evidence for simultaneous and backward excitatory conditioning poses obvious difficulties for these views. For example, the information hypothesis (Egger \& Miller, 1962) holds that for a stimulus to acquire conditioned strength, it must be a reliable and nonredundant predictor of the US. A CS that followed a US could not be a predictor of the US and should not acquire conditioned strength.
Also, a CS simultaneously paired with a US should not acquire conditioned strength because it is a redundant predictor of US onset. The present results demonstrate that conditioning does occur in these situations, and therefore, that a CS need not be a reliable and nonredundant predictor of a US in order to be conditioned.

A similar problem arises for contingency theory (Rescorla, 1967), which stated that excitatory conditioning occurs to the extent that USs occur more frequently during or at some specified time after the CS than in other comparable time periods. This theory, by definition, excluded the possibility of excitatory backward conditioning. The demonstration of excitatory backward conditioning above calls into question such a restrictive definition.

Although backward and simultaneous excitatory conditioning do raise difficulties for many views of classical conditioning, there are several ways to reconcile the data with these theories. Cautela (1965) suggested that backward conditioning occurred only when aversive stimuli were used. He hypothesized that in a backward procedure, although the CS followed the US, the CS may still precede the perceived aftereffects of the US. Thus, backward conditioning may really reflect forward pairings of the CS with the perception of pain caused by the US.

Another possibility is that the backward CS becomes excitatory through a second-order conditioning process in which it precedes (or is simultaneously compounded with) apparatus cues that have just been made aversive through the presentation of the US (cf. Mowrer \& Aiken, 1954). This hypothesis predicts stronger excitatory conditioning when CS immediately follows US than when CS follows US by a long interval (e.g., explicitly unpaired control, EUB). The reason is that in the latter instance excitation conditioned to apparatus cues has more time to extinguish. Hence, second-order conditioning should be weaker.

The exact mechanisms through which the backward CS becomes excitatory are obviously still unknown, but the evidence that it can become excitatory under some conditions is beginning to mount. The present results contribute to that evidence in showing that the conditioning favorable for excitatory backward conditioning include the onetrial procedure, a procedure entirely uncomplicated by remote forward or backward CS-US associations. ${ }^{1}$

Our results do not, however, contradict earlier reports that backward (Moscovitch \& LoLordo, 1968; Siegel \& Domjan, 1971, 1974) and simultaneous (Siegel \& Domjan, 1971, Experiment 1$)^{2}$ procedures can produce an inhibitory CS. These latter studies used multitrial procedures, differing from the present one both in terms of the total number of trials and the number of trials per session, as well as in terms of 
other parameters. Theoretical speculation about why these different procedures should produce opposite outcomes has already begun to appear. (Wagner \& Terry, 1975).

\section{REFERENCES}

CAUTELA, J. R. The problem of backward conditioning. Journal of Psychology, 1965, 60, 135-144.

Domian, M., \& SIEgel, S. Conditioned suppression following CS preexposure. Psychonomic Science, 1971, 25, 11-12.

EgGer, M. D., \& Miller, N. E. Secondary reinforcement in rats as a function of information value and reliability of the stimulus. Journal of Experimental Psychology, 1962, 64, 97-104.

Gormezano, I., \& Moore, J. W. Classical conditioning. In M. H. Marx (Ed.), Learning: Processes. Toronto: Collier-MacMillan, 1969. Pp. 121-203.

HARRIS, J. D. Forward conditioning, backward conditioning, pseudoconditioning and adaptation to the conditioned stimulus. Journal of Experimental Psychology, 1941, 28, 491-502.

Heth, C. D., \& Rescorla, R. A. Simultaneous and backward fear conditioning in the rat. Journal of Companative and Physiological Psychology, 1973, 83, 434-443.

Hulc, C. L. Principles of behavior. New York: Appleton-CenturyCrofts, 1943.

JoNES. J. E. Contiguity and reinforcement in relation to CS.US intervals in classical aversive conditioning. Psychological Review. 1962, 69. 176-187.

Keith-Lucas, T., \& Guttman, N. Robust single-trial delayed backward conditioning. Journal of Comparative and Physiological Psychology, 1975, 88, 468-476.

Kimble, G. A. Hilgard and Marquis' conditioning and learning. New York: Appleton-Century-Crofts, 1961.

MATSUmiYA. Y. The effects of US intensity and CS-US pattern on conditioned emotional response. Japanese Psychological Research, 1960, 2, 35-42.

Moscovitch, A., \& LoLordo, W. M. Role of safety in the Pavlovian backward fear conditioning procedure. Journal of Comparative and Physiological Psychology, 1968, 66, 673-678.

Mowrer, O., \& Aiken, E. G. Contiguity vs. drive-reduction in conditioned fear: Temporal variations in conditioned and unconditioned stimulus. American Journal of Psychology, 1954, 67, 26-38.

Pavlov, I. P. Conditioned Reflexes. (Trans. G. V. Anrep). London: Oxford University Press, 1927.

Plotxun, R. C., \& OAKLEY, P. A. Backward conditioning in the rabbit (Oryctolagus cuniculus). Joumal of Comparative and Physiological Psychology, 1975, 88, 586-590.

Razran, G. Backward conditioning. Psychological Bulletin, 1956, 55, 55-69.

Razran, G. Mind in evolution. Boston: Houghton-Mifflin, 1971.

Rescorla, R. A. Pavlovian conditioning and its proper control procedures. Psychological Review, 1967, 74, 71-80.

Rescorla, R. A. Pavlovian conditioned inhibition. Psychological Bulletin, 1969, 72, 77.94.

ResCorla, R. A., \& LoLoRdo, V. M. Inhibition of avoidance behavior. Joumal of Comparative and Physiological Psychology, 1965, 59, 406-412.

Rescorla, R. A., \& Wagner, A. R. A theory of Pavlovian conditioning: Variations in the effectiveness of reinforcement and nonreinforcement. In A. H. Black \& W. F. Prokasy (Eds.), Classical conditioning II. New York: Appleton-Century-Crofts, 1972.
Siegel, S., \& Doman, M. Backward conditioning as an inhibitory procedure. Learning and Motivation. 1971, 2, 1-11.

Siegel, S., \& Domjan, M. The inhibitory effect of backward conditioning as a function of the number of backward pairings. Bulletin of the Psychonomic Society, 1974, 4, 122-124.

TARPY, R. M. Basic principles of leaming. Glenview: Scott, Foresman, 1975.

VOGEl, J. R., \& SPEAR, N. E. Interaction of reward magnitude and conditioned fear on the consummatory response. Psychonomic Science, 1966, 5, 263-264.

W AGner. A. R., \& TERRY, W. S. Backward conditioning to a CS following an expected vs. a surprising UCS. Animal Learning \& Behavior, 1975, 3, 370-374.

\section{NOTES}

1. After this research was completed, Keith-Lucas and Guttman (1975) also reported finding excitatory fear conditioning in a one-trial backward conditioning procedure. They suggested that the conditioning they obtained depended on an evolved capacity of the rat to associate certain classes of stimuli with exteroceptive pain regardless of the temporal ordering of the stimuli and the pain. The stimuli believed effective were those resembling predators of conspecific aggressors (their CS was a rubber hedgehog). The present results suggest, however, that onetrial excitatory backward conditioning is not limited to such a class of stimuli.

2. There seems to be disagreement in the literature as to what constitutes a backward or simultaneous pairing. The convention we have followed is to define procedures in terms of the interstimulus interval (ISI). The ISI is said to be positive when CS onset precedes US onset, zero when CS and US onsets begin together, and negative when CS onset follows US onset. We equate positive, zero, and negative ISIs with forward, simultaneous, and backward procedures, respectively. Within these divisions, subclasses can be distinguished in terms of the relationship between features of the CS and US other than their onset. Forward trace procedures are forward procedures in which CS offset precedes US onset; forward delay procedures are forward procedures in which CS offset is simultaneous with or follows US offset (cf. Gormezano \& Moore, 1969; Kimble, 1961, p. 47). One subclass of backward procedures that has been recognized is the cessation procedure in which CS onset follows US onse1 but precedes US offset (cf. Razran, 1956, 1971). Subclasses of simultaneous procedures seem not to have been named but could be on the basis of whether CS offset preceded, coincided with, or followed US offset. Although the classification scheme adopted here is consistent with textbook usage (e.g., Kimble, 1961 , pp. $47-48 ; 156$ ) and with a large portion of the conditioning literature, exceptions to it appear in recent writings. Siegel and Domjan (1971, Experiment 1) described as a backward procedure one in which CS and US began simultaneously but CS offset occurred after US offset. Heth and Rescorla (1973) described as a simultaneous procedure one in which CS onset began after US onset but before US offset. In the classification scheme used here, the procedure of Siegel and Domjan was a member of the simultaneous class, while that of Heth and Rescorla was the cessation procedure, a member of the backward class.

(Received for publication August 14, 1975; revision accepted February 23, 1976.) 